\title{
Study of the Mechanical Performance of a Recycled Aggregate Concrete with Admixture Addition
}

\author{
Larbi Belagraa $^{1 *}$, Miloud Beddar ${ }^{2}$ \\ ${ }^{1}$ Laboratory of Materials and Electronic Systems (LMSE), Faculty of Sciences and Technology, \\ Bordj Bou Arreridj University, Bordj Bou Arreridj, Algeria \\ ${ }^{2}$ Department of Civil Engineering, M’Sila University, M’Sila, Algeria \\ Email: *Lbelagraa@yahoo.fr, beddarm@yahoo.fr
}

Received January 13, 2013; revised March 2, 2013; accepted March 10, 2013

Copyright (C) 2013 Larbi Belagraa, Miloud Beddar. This is an open access article distributed under the Creative Commons Attribution License, which permits unrestricted use, distribution, and reproduction in any medium, provided the original work is properly cited.

\begin{abstract}
The needs of the construction sector are still increasing for concrete. However the shortage of natural resources of aggregate could be a problem for the concrete industry. In addition, the negative impact on the environment is due to the construction demolition; where disposal wastes create a severe ecological and environmental hazard. In the last decade, a major interest has been developed for the reuse of recycled aggregates that present more than $70 \%$ of the concrete volume. The reused products should fulfill the requirements of lower cost and better quality, in order to establish its role in the concrete. The aim of this study is to assess the effect of the local admixtures on the mechanical behavior of recycled aggregate concrete (RAC). Physical and mechanical properties of RAC were investigated including density, compressive and flexural strength. The non-destructive test methods (NDT: pulse-velocity and rebound hammer) were used to determine the concrete strength. The results obtained were compared with crushed aggregate concrete (CAC) using the normal compressive testing machine test method. Thus, the convenience of indirect tests in the case of a recycled aggregate concrete were demonstrated.
\end{abstract}

Keywords: Recycled Concrete Aggregate; Demolition Waste; Non-Destructive Tests; Mechanical Strength; Admixture

\section{Introduction}

Concrete is still the mostly used material by the construction industry and the highway construction sector. The industry need in this field for such a material has increased over the years. The conservation of natural resources coupled with the increase in aggregate requirement for construction, further to the increasing cost of landfill beside the negative impact regarding the preservation of environment. These considerations urged the researchers and actors in the construction domain to focus their efforts on the management wastes resulting from demolition [1,2].

In fact of the use of recycled aggregate concrete (RAC) is acquiring particular interest in civil construction as regards to sustainable development. Many studies demonstrate the feasibility of the use of crushed concrete as coarse aggregate [3-9].

The reuse of recycled aggregate that comes from construction waste presents a major interest for users and

\footnotetext{
"Corresponding author.
}

researchers of concrete as it occupies $70 \%$ of concrete. The study herein concerns an investigation of the properties of recycled aggregate concrete (RAC) incorporating admixtures to formulate a much more durable concrete. The experimental programme has the objectives of studying the effect of a superplasticizer (S120) on the mechanical strength (Rc) of RAC. The non-destructive test methods were carried out to assess this hardened property and to see if methods such as rebound hammer and ultrasonic techniques can be conveniently adapted in this case [10]. Other physical properties like the density of RAC were studied. The third aim of this research study is the comparison of the performance of recycled aggregate concrete and a concrete based on ordinary crushed aggregate (CAC).

The experimental programme to achieve these objectives includes a series of tests, such as to formulate a recycled aggregate concrete having the performance of a normal concrete with crushed stone aggregate.

Recycled concrete specimens were cast using different percentages of admixtures $0 \%, 1 \%, 1.5 \%$ and $2 \%$. The 
ordinary concrete was prepared with similar aggregate size (8/16 and 16/25) and identical admixture dosages. Tests of the specimens at age of 28 days using a compressive testing machine and non-destructive methods were used to evaluate the mechanical response of concrete. In all mixes a constant workability of $50 \mathrm{~mm}$ was maintained using the slump test method [11].

\section{Materials and Equipments}

\subsection{Sand}

The sand used in this study was a clean siliceous and fine sand of fraction 0/5 mm from Boussaada region [12]. Its characteristics are reported in Table $\mathbf{1}$ and the grading curve is shown in Figure 1.

\subsection{Gravel}

Ordinary gravel was obtained from crushed limestone rock and delivered from the quarry of COSIDER El Euch region (250 km south of Algiers).The gravel fraction used in this study was $8 / 16,16 / 25$ in proportions of $40 \%$ and $60 \%$ respectively [13]. The characteristics are shown in Table 1 and the grading curve in Figure 1.

\subsection{Recycled Aggregate}

Pieces of old concrete specimens were crushed using a steel hammer provided by the civil engineering laboratory. The size of the particles maintained for this investigation was $8 / 16$ an $16 / 25$ at a percentage of $40 \%$ and $60 \%$. The characteristics of the recycled aggregate are reported in Table 1 and Figure 2.

\subsection{Cement}

The cement used was type CPJ 42.5 delivered from Ain

Table 1. Some characteristics of the sand, ordinary crushed aggregates (CA) and recycled aggregate (RA).

\begin{tabular}{|c|c|c|c|c|c|}
\hline Materials & $\begin{array}{l}\text { Specific } \\
\text { weight } \\
\rho s(\mathrm{Kg} / \mathrm{l})\end{array}$ & $\begin{array}{c}\text { Bulk } \\
\text { density } \\
P(\mathrm{Kg} / \mathrm{l})\end{array}$ & $\begin{array}{l}\text { Compactness } \\
\text { (Solid content) } \\
(C)^{*}(\%)\end{array}$ & $\begin{array}{l}\text { Porosity } \\
(P)^{* *} \\
(\%)\end{array}$ & $\begin{array}{c}\text { Sand } \\
\text { modulus } \\
\left(E_{s}\right)(\%)\end{array}$ \\
\hline Sand & 2.56 & $1.6 / 1.7$ & $64.42 / 70.76$ & $36.58 / 29.24$ & 73.40 \\
\hline $\begin{array}{l}\text { Crushed } \\
\text { agg }\left(G_{C A}\right) \\
\quad 8 / 16\end{array}$ & 2.54 & 1.33 & 50.97 & 49.06 & - \\
\hline $\begin{array}{c}\text { Crushed } \\
\text { agg } \\
\left(G_{C A}\right) 16 / 25\end{array}$ & 2.57 & 1.31 & 51.85 & 48.16 & - \\
\hline $\begin{array}{l}\text { Recycled } \\
\text { agg (ra) } \\
8 / 16\end{array}$ & 2.40 & 1.24 & 48.97 & 51.03 & - \\
\hline $\begin{array}{l}\text { Recycled } \\
\text { agg } \\
\text { (ra)16/25 }\end{array}$ & 2.34 & 1.12 & 49.93 & 50.07 & - \\
\hline
\end{tabular}

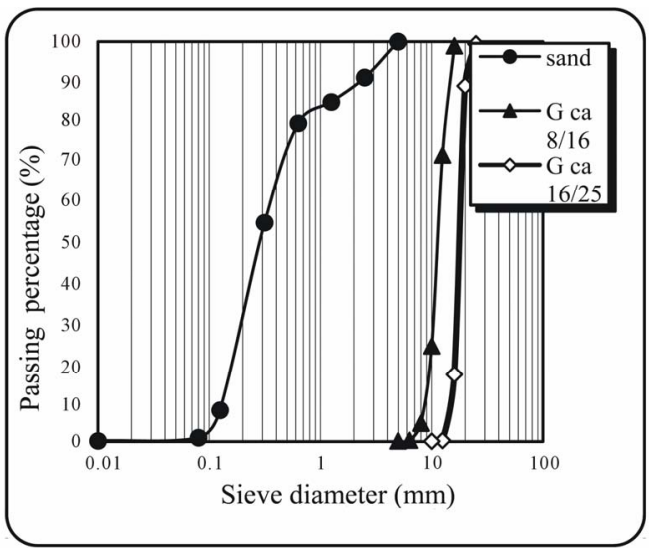

Figure 1. Grain size distribution of the sand and crushed aggregate (ca).

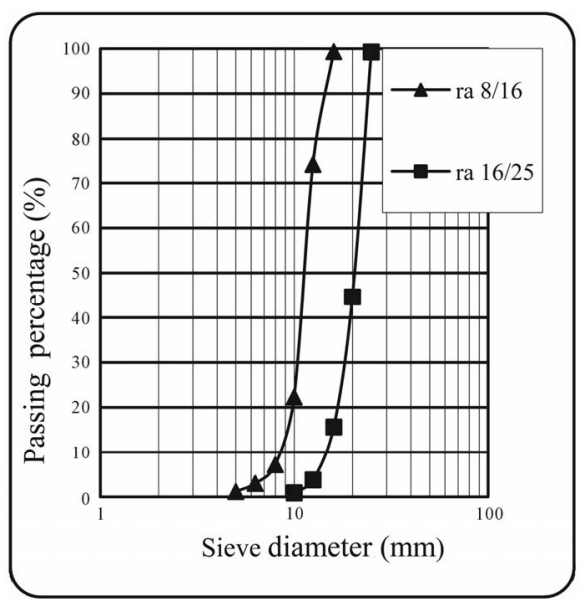

Figure 2. Grain size distribution of recycled aggregate (ra).

Kebira cement plant and widely used in the construction sector in Algeria in accordance with standard [14].

\subsection{Admixtures}

The admixtures is a local superplasticizer product Medaplast (120) manufactured by Granitex in Oued Smar near Algiers. It is a brownwish emulsion having a relative density of 1.2 and a $\mathrm{pH}$ ranging from 8 to 8.5 [15].

\subsection{Water}

A tap water from the civil engineering laboratory was used for concrete batching.

\subsection{Concrete Mix}

The concrete mix proportions used were for a grade 350 mix, determined by the absolute volume [16].

\begin{tabular}{ll} 
Cement & $324 \mathrm{~kg} / \mathrm{m}^{3}$ \\
Sand & $565 \mathrm{~kg} / \mathrm{m}^{3}$ \\
Gravel 8/16 & $565 \mathrm{~kg} / \mathrm{m}^{3}(40 \%)$ \\
\multicolumn{1}{c}{$16 / 25$} & $760 \mathrm{~kg} / \mathrm{m}^{3}(60 \%)$
\end{tabular}


Water (total) $180 \mathrm{~L}$ (This quantity takes into account the degree of aggregate absorption).

\section{Testing}

\subsection{Workability}

The method used to assess the workability for both ordinary and recycled concrete was the slump test method [11]. A workability of about $50 \mathrm{~mm}$ was maintained for all mixes.

\subsection{Compressive Strength}

Compression tests were carried out on cubic specimens $(150 \times 150 \times 150) \mathrm{mm}^{3}$ Tests were done using the hydraulic press model "STRASSENTEST FHF" [17]. The specimens were centred on the tray of the press and a continuous load was applied. The ultimate compression load for each concrete cube was recorded at 28 days age (Tables 2 and 3).

\subsection{Rebound Hammer Test}

The specimens were placed in the centre of the hydraulic machine press; a continuous load was applied and maintained within a range of 10 to $20 \mathrm{KN}$. The rebound hammer test was carried out on five different points spaced at $2 \mathrm{~cm}$ intervals on both faces of the cubic specimens [18]. The final result from the test was calculated using the following equation:

$$
R S=\sum_{i=1}^{n} S / n
$$

with: $n$-Number of tests carried out on both faces of the cube; $S$-The recorded value of rebound hammer.

\subsection{Ultrasonic Method}

The pulse velocity test was carried out on the two opposite sides of the specimens $(150 \times 150 \times 150) \mathrm{mm}^{3}$ using direct transmission [19]. The transit time $t$ in $\mu$ s was recorded and the velocity $V$ is measured as; (see Tables 2 and 3).

$$
V=d / t
$$

$V$-Velocity in $\mathrm{km} / \mathrm{sec}$.

$d$-The distance between the two transducers.

$t$-The transit time in $\mu \mathrm{s}$.

\section{Analysis of Results}

\subsection{Presentation of Results}

In this study the concrete mixes have been prepared according to the method of absolute volume [16]. The following percentages of admixtures $0 \%, 1 \%, 1.5 \%$, and $2 \%$ were chosen. The cubic specimens $(150 \times 150 \times 150)$
Table 2. Results of mechanical strength and density for recycled aggregate (RAC) at 28 days of age.

\begin{tabular}{cccccccc}
\hline $\begin{array}{c}\text { Adm } \\
\text { ixtures }\end{array}$ & $\begin{array}{c}\text { Bulk density } \\
\left(\mathrm{Kg} / \mathrm{m}^{3}\right)\end{array}$ & $\begin{array}{c}\text { Velocity } \\
(\mathrm{km} / \mathrm{s})\end{array}$ & \multicolumn{4}{c}{$\begin{array}{c}\text { Strength } \\
\left(\mathrm{N} / \mathrm{mm}^{2}\right)\end{array}$} \\
\hline$\%$ & $\rho$ & $V$ & $S$ & $R_{S}(\mathrm{rac})$ & $R_{s u}(\mathrm{rac})$ & $R_{c}(\mathrm{rac})$ \\
0 & 2311 & 4.13 & 22.36 & 11.80 & 11.40 & 25.62 \\
1 & 2306 & 4.20 & 27.20 & 20.00 & 20.50 & 29.98 \\
1.5 & 2345 & 4.50 & 28.30 & 21.80 & 25.14 & 39.10 \\
2 & 2355 & 4.70 & 28.43 & 21.50 & 29.33 & 34.50 \\
\hline
\end{tabular}

Table 3. Results of mechanical strength and density for Crushed Aggregate Concrete (CAC) at 28 days of age.

\begin{tabular}{ccccccc}
\hline $\begin{array}{c}\text { Adm } \\
\text { ixtures }\end{array}$ & $\begin{array}{c}\text { Bulk density } \\
\left(\mathrm{Kg} / \mathrm{m}^{3}\right)\end{array}$ & $\begin{array}{c}\text { Velocity } \\
(\mathrm{km} / \mathrm{s})\end{array}$ & \multicolumn{4}{c}{$\begin{array}{c}\text { Strength } \\
\left(\mathrm{N} / \mathrm{mm}^{2}\right)\end{array}$} \\
\hline$\%$ & $\rho$ & $V$ & $S$ & $R_{s}(\mathrm{rac})$ & $R_{s u}(\mathrm{rac})$ & $R_{c}(\mathrm{rac})$ \\
0 & 2395 & 4.43 & 23.40 & 14.50 & 19.00 & 32.00 \\
1 & 2434 & 4.83 & 28.63 & 21.80 & 22.50 & 46.32 \\
1.5 & 2455 & 4.74 & 27.03 & 20.03 & 28.20 & 38.96 \\
2 & 2455 & 4.89 & 28.26 & 21.60 & 33.20 & 37.77 \\
\hline
\end{tabular}

$\mathrm{mm}^{3}$ were cast and cured in water to be tested at 28 days age. Initially specimens measuring $150 \times 150 \times 150 \mathrm{~mm}^{3}$ with different admixture dosages were studied by the means of the non destructive tests (ultrasonic and rebound hammer) and finally the compressive tests were carried out on these concrete cubes. The value of compressive strength $R c$ is compared to $R_{s u}$ the combined value obtained of ultrasonic $(V)$ method and the rebound hammer reading $(S)$ (see Tables 2 and 3 ).

The due strength $\mathrm{R}_{\mathrm{su}}$ is then assessed according to the formula of Feret [16].

$$
R_{s u}=\left[S / n_{0}+n_{1} \cdot S-n_{2} \cdot V\right]^{2}
$$

$n_{0}=3.64, S$-Rebound hammer reading.

$n_{1}=0.023, R_{s u}$-Ultrasonic-rebound hammer resistance $\left(\mathrm{N} / \mathrm{mm}^{2}\right)$.

$$
n_{2}=0.56, V \text {-Velocity } \mathrm{Km} / \mathrm{sec} \text {. }
$$

\section{Results and Discussion}

\subsection{Compressive Strength}

According to Figure 3 the behaviour of RAC shows the same trend of strength development for all dosages of admixture at 28 days. However for a dosage of $1 \%$ admixture the recycled concrete gives a lower compressive strength compared to normal concrete with crushed stone aggregate. The values of strength registered were 29.98 and 46.32, respectively.

For admixture contents over $1.5 \%$ the recycled concrete showed similar comparative values to ordinary concrete. Thus, performance of RAC similar to ordinary 


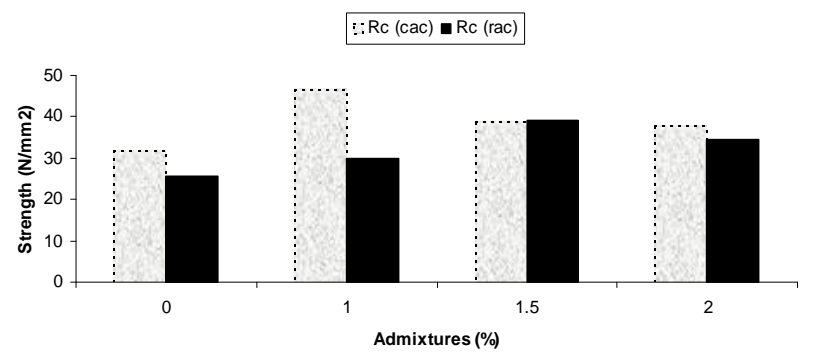

Figure 3. The compressive strength Rc in function of the admixture content for recycled (RAC) and normal concrete (CAC) (compression test) at 28 days age.

concrete can be achieved with the incorporation of admixtures. Khaldoun Rahal, reported that the trend in the development of compressive and tensile strength and strain at peak stress in recycled aggregate showed; were similar compared to natural aggregate [4].

\subsection{Rebound Hammer Results}

Although the rebound hammer test results are affected by many factors, such as the mix characteristics (cement type, content and the aggregate type) or the member characteristics (mass, density, surface type, age, curing type and surface carbonation), only the main factor of aggregate type is considered in this study $[10,16]$. The rebound hammer test results in Figure $\mathbf{4}$ show that the $0 \%$ admixtures dosage gives the lowest value of strength. It is noted that there is a slight increase of strength for higher percentages admixture of $1 \%, 1.5 \%$ and $2 \%$.

The recycled concrete RAC proved to give lower reading results compared to normal concrete (CAC). This could be related to the reliability of rebound hammer indirect test that is not convenient for accurate measurements of real strength for concrete structures compared to compression test.

\subsection{Ultrasonic Tests}

Figure 5 illustrates that what ever the type of aggregate used, strength development is similar for normal concrete and RAC. Furthermore the compressive strength of ordinary concrete is superior to the results given for RAC. The effect of admixtures on the mechanical strength is more advantageous for recycled aggregate concrete. The contribution of the admixtures to increasing strength is marked. This is due to the improvement of workability of fresh concrete, as well as water reduction in concrete mix resulting in an improvement of the resistance of concrete matrix.

\subsection{Density}

Figure 6 shows that the bulk density of CAC presented a slight increase in hardened specimens compared to recycled concrete aggregate (RAC). This may be related to

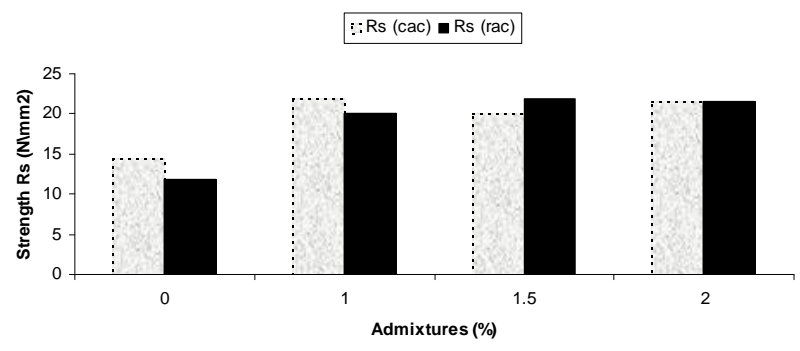

Figure 4. Strength Rs against admixture content (\%) for (RAC) and (CAC) at 28 days age (rebound hammer test).

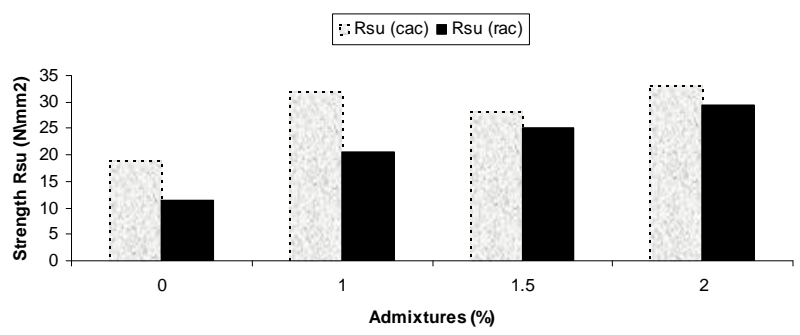

Figure 5. Strength Rsu against adimixtures content for RAC \& CAC at 28 days age (ultrasonic test).

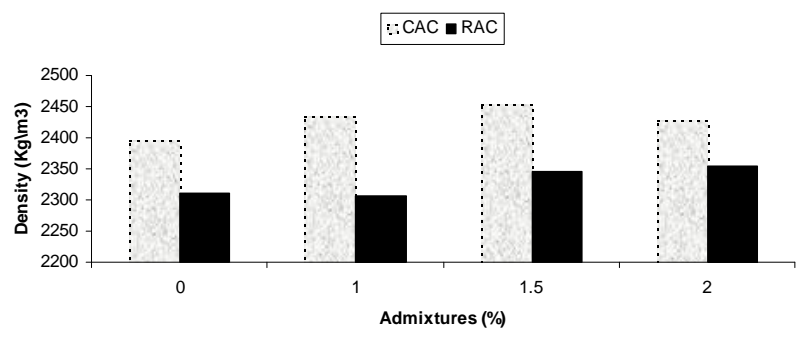

Figure 6. The density in function of admixture percentage for the recycled and normal concrete.

the heavy density of the crushed aggregate type; which is more compact. This is more evident for dosages of $1 \%$, $1.5 \%$ and $2 \%$ of admixture $\left(2345,2455 \mathrm{~kg} / \mathrm{m}^{3}\right)$ for RAC and CAC, respectively. For the percentage of admixtures of $1.5 \%$ the decrease is about $100 \mathrm{~kg} / \mathrm{m}^{3}$. In fact the density of RAC is significantly lighter compared to normal concrete for the identical admixture incorporation as reported in other research work. Khatib, J M, reported that a decrease in the density was observed when crushed concrete was used for recycled concrete mixes [20].

\section{Conclusions}

In light of this study with the objective of studying the effect of admixtures (Medaplast 120) on the mechanical response of RAC compared to crushed aggregate concrete (CAC), where the assessment of the strength used indirect tests (ultrasonic and rebound hammer) methods beside a compression machine test. The interpretation of these results leads to the following conclusions:

1) The compressive strength development is similar for both recycled aggregate concrete (RAC) and crushed 
aggregate concrete (CAC) with the same admixture dosages.

2) The recycled aggregate concrete shows the same performance compared to normal concrete for an admixture optimal dosage of $1.5 \%$.

3) The density of crushed aggregate concrete presents a slight increase in comparison to recycled aggregate concrete. This is attributed to the type of recycled aggregate type with higher air content and lower density.

4) Non-destructive tests can be used to assess the strength of RAC, but a correction coefficient is required to obtain a similar value to the compressive strength given by the compression machine test.

5) In general, there is an improvement of recycled aggregate concrete strength when combined with admixtures compared to normal concrete without admixture incorporation.

\section{Acknowledgements}

The authors gratefully acknowledge the laboratory staff of civil engineering department at the university of M'sila for their support throughout the research work undertaken of this study.

\section{REFERENCES}

[1] T. C. Hansen, "Recycling of Demolished Concrete and Masonry,” 2nd Edition, Chapman and Hall, London, 1996.

[2] RILEM Recommendation, "121-DRG Guidance for Demolition and Reuse of Concrete and Masonry, Specifications for Concrete with Recycled Aggregates,” Materials and Structures, Vol. 27, 1994, pp. 557-559.

[3] ACI Committee, "Removal and Reuse of Hardened Concrete,” ACI Material Journal, Vol. 3, No. 99, 2002, pp. 250-300.

[4] K. Rahal, "Mechanical Properties of Concrete with Recycled Coarse Aggregate,” Building Environment, Vol. 42, No. 1, 2007, pp.407-415. doi:10.1016/j.buildenv.2005.07.033

[5] M. C. Limbachiya, E. Marrocchino and A. Koulouris, "Chemical-Mineralogical Characterisation of Coarse Recycled Concrete Aggregate,” Waste Management, Vol. 201, 2007, pp. 8-27.
[6] V. W. Y. Tam, K. Wang and C. M. Tam, “Assessing Relationships among Properties of Demolished Concrete, Recycled Aggregate and Recycled Aggregate Concrete Using Regression Analysis,” Journal of Hazardous Materials, Vol. 152, No. 2, 2008, pp.703-714. doi:10.1016/j.jhazmat.2007.07.061

[7] A. K. Padmini, K. Ramamurthy and M. S. Mathews, "Influence of Parent Concrete on the Properties of Recycled Aggregate Concrete," Construction and Building Materials, Vol. 23, No. 2, 2009, pp. 829-836. doi:10.1016/j.conbuildmat.2008.03.006

[8] S. W. Tabsh and A. S. Abdelfatah, "Influence of Recycled Concrete Aggregates on Strength Properties of Concrete," Construction and Building Materials, Vol. 23, 2009, pp. 1163-1167.

[9] M. L. Berndt, "Properties of Sustainable Concrete Containing Fly Ash, Slag and Recycled Concrete Aggregate," Construction and Building Materials, Vol. 23, 2009, pp. 2606-2613.

[10] T. H. Bungey, “Testing of Concrete Structures," Surrey University Press, 1982.

[11] NA EN 12350-2, “Slump Test (Abrams Cone),” 2009.

[12] NA EN 933-1, “Tests for Geometrical Properties of Aggregates-Determination of Particle Size DistributionSieving Method, (2000) and NA EN 933-2 (1999), Particle Size Distribution.”

[13] NA EN 1097-6, "Tests for Mechanical and Physical Properties of Aggregates, Determination of Particle Density and Water Absorption," 2000.

[14] NA EN 197-1, “Test for cements, specifications.”

[15] NA EN 934-2, “Admixtures for Concrete and Mortars, Definitions, Specifications for Use,” 2001.

[16] G. Dreux et J. Festa, “Nouveau Guide du Béton, ” Edition Eyrolles, 1995.

[17] NA EN 12390-3, "Testing Hardened Concrete. Part 3: Compressive Strength of Test Specimens,” 2003.

[18] NA EN 12398-6, “Testing Hardened Concrete, Rebound Hammer,” 2003.

[19] NA EN 13296-6, “Testing of Concrete, Ultrasonic Strength at 28 Days,” 2003.

[20] J. M. Khatib, "Properties of Concrete Incorporating Fine Recycled Aggregate," Cement and Concrete Research, Vol. 35, No. 4, 2005, pp. 763-769. doi:10.1016/j.cemconres.2004.06.017 